\title{
Desafios da Política Patrimonial no Contexto da Timbila Moçambicana
}

https://doi.org/10.21814/uminho.ed.48.15

Vítor Chibanga

Universidade Politécnica, Maputo, Moçambique vchibanga@yahoo.com.br

\section{Resumo}

Com base nas ratificações da Convenção Para a Salvaguarda do Património Cultural Imaterial (2003) e da Convenção Para a Protecção e Promoção da Diversidade das Expressões Culturais (2005), Moçambique passou a ter obrigação de assumir uma série de medidas de salvaguarda tais como: identificação, documentação, preservação, protecção, promoção, divulgação e transmissão do seu património. É neste âmbito que o presente texto tem como propósito analisar os desafios da timbila enquanto património cultural imaterial moçambicano e mundial, problematizando as medidas necessárias para sua salvaguarda. Para tanto, será feita uma contextualização histórica sobre os factores que concorreram para a elevação da timbila a património cultural da humanidade em 2005; serão analisadas as relações estabelecidas entre 0 Estado e as comunidades praticantes, tendo em conta os discursos oficiais em volta da timbila e como estes ressoam perante os praticantes; também nos interessa reflectir sobre as práticas promovidas por instituições do Estado, tais como: o ensino da timbila, a inventariação, e a preservação do mwenje que é a matéria-prima para a construção dos instrumentos.

\section{Palavras-chave}

timbila, Moçambique, património, salvaguarda 


\section{Desafios da Política Patrimonial no Contexto da Timbila Moçambicana}

O objecto deste artigo enquadra-se em torno da concepção da timbila enquanto património cultural da humanidade. Este objecto faz parte de um trabalho que venho desenvolvendo desde minha graduação em 2011 e que resultou no texto Papel da Comunicação no Processo de Salvaguarda da Timbila Chope Como Património da Humanidade (Chibanga, 2011). Objetivando aprofundar esta pesquisa e aproveitando minha experiência como colaborador do Instituto de Investigação Sócio-Cultural, ingressei no mestrado em performances culturais (Universidade Federal de Goiás [UFG]) cuja linha de pesquisa é "teorias e práticas da performance". Portanto, este texto, parte tanto das minhas pesquisas académicas quanto daquilo que pude observar enquanto colaborador de um órgão que trabalha com a cultura em Moçambique.

Moçambique ratificou as convenções da Unesco em 2003 e 2005 e, com base nestas ratificações, o país passou a ter obrigação de assumir uma série de medidas de salvaguarda e a timbila enquanto património cultural imaterial possui medidas de salvaguarda específicas devido às suas peculiaridades culturais. No âmbito desta reflexão se faz necessário realizar uma descrição sobre a relevância da timbila, e esta análise se justifica pelo facto de Moçambique, através do Ministério da Cultura, no âmbito da elaboração da sua candidatura da timbila a património da humanidade no ano de 2004, ter definido como prioridade (Wane, 2010, pp. 26-27):

- a preservação do mwenje, que é a madeira necessária à fabricação da mbila e que atualmente se encontra quase em processo de extinção;

- a introdução da timbila no sistema nacional de educação;

- acções de turismo cultural na região de Zavala, de onde a timbila é a cultura típica;

- mecanismos de geração de renda para os artistas;

- construção de um centro cultural temático no distrito de Zavala, no qual se possa preservar a memória histórica e se produzir instrumentos, leccionar.

Com base neste plano de acções do Estado, propomos uma reflexão sobre as peculiaridades da timbila que é um instrumento que tem características que o distinguem de outros instrumentos similares executados em outros países de África e que, muitas vezes, são identificados por outros nomes. É neste âmbito que o presente texto tem como propósito analisar os desafios da timbila enquanto património cultural imaterial moçambicano e mundial, problematizando as medidas necessárias para a sua salvaguarda. Para tanto, será feita uma descrição e contextualização histórica da timbila, serão analisadas as relações estabelecidas entre o Estado e as comunidades praticantes, assim como serão problematizadas algumas práticas levadas a cabo pelas instituições do Estado como a educação, a inventariação e a preservação do mwenje, que é a matéria-prima para a construção dos instrumentos. 


\section{A Timbila e o Contexto Histórico}

No contexto da etnia chope, segundo Lutero (1980, p. 40), timbila é o termo usado para o plural de mbila, que também é o nome de um instrumento musical pertencente ao grupo dos xilofones e, ao mesmo tempo, nome de uma dança que acompanha os ritmos produzidos pela orquestra instrumental, praticada na província de Inhambane pela etnia chope. Diferentes pesquisadores evidenciam que os chopes "dedicam-se à música, desde há já muitos séculos, sempre com uma paixão extraordinária” (Munguambe, 2000, p. 58).

O registro da timbila, segundo Jopela (2005), teve o seu início em 1560, através da carta escrita pelo padre jesuíta André Fernandes aos seus superiores em Portugal e Goa. Na tal carta, designava o povo que encontrou nos quadrantes das terras chopes de "gentes afortunadas", devido à sua capacidade de compor, cantar e fazer arte. Este registo constitui como um marco da etnografia da música em Moçambique. Embora Henri Junod (1996) tenha falado sobre timbila, o estudo que trouxe uma análise mais profunda sobre esta manifestação foi o trabalho desenvolvido pelo etnomusicólogo Hugh Tracey (1949), que chamou a atenção da comunidade científica sobre a singularidade contida na música e dança da timbila, enquanto uma expressão cultural e incentivou o aprofundamento de outras pesquisas na área.

No período pós-independência, os músicos chopes (assim como imensa parte da população moçambicana) viveram momentos difíceis da sua história, pois Moçambique esteve mergulhado no conflito armado entre a Frente de Libertação de Moçambique (Frelimo) e a Resistência Nacional de Moçambique (Renamo). A Renamo liderou o sangrento conflito armado que iniciou em 1976 e que só teve fim 16 anos depois, provocando cerca de 1.000 .000 de mortos e cerca de 5.000 .000 de deslocados, além de grande destruição das infra-estruturas do país, especialmente nas zonas rurais. Devido à guerra, o "M'saho", maior evento cultural de timbila que ocorre no distrito de Zavala, na vila de Quissico, desde o período colonial, durante a última semana do mês de agosto foi interrompido, pois não havia condições para que as orquestras de timbila pudessem actuar num contexto de guerra. Como consequência, vários dançarinos e tocadores de timbila emigraram para zonas mais seguras. Uns emigraram para trabalhar nas minas da África do Sul que ofereciam melhores condições e outros para as cidades capitais do país.

O efeito nefasto da guerra interferiu negativamente na transmissão sistemática dos saberes relacionados à timbila. Os mais velhos considerados "bibliotecas vivas" pararam de exercer o seu papel social de transmissão dos saberes inerentes à timbila aos mais novos, comprometendo assim o ciclo de salvaguardo. Foi neste âmbito que o Estado, após ter identificado e reconhecido o perigo de extinção deste legado patrimonial, decidiu por via do Ministério da Cultura em colaboração com a Direcção Nacional da Cultural, com o Arquivo do Património Cultural (ARPAC), e com o apoio da Cinemate, Associação de Amigos de Zavala (Amizava), Rádio Televisão Portuguesa (RTP), Televisão de Moçambique (TVM), elaborar e submeter a candidatura da timbila chope à Unesco, para concorrer a património cultural da humanidade no ano 
de 2004. No culminar desse processo, a Unesco proclamou a timbila chope como património oral e imaterial da humanidade no dia 25 de setembro de 2005, em Paris.

Face às ameaças em torno da timbila, uma das medidas de salvaguarda foi fortalecer cada vez mais a prática do "M'saho", que havia sido restaurado em 1994, logo após o fim do conflito armado que terminou em 1992, com o Acordo Geral de Paz. A instituição responsável para a restauração do "M'saho" foi Amizava em parceria com o governo distrital de Zavala. É com base na restauração do "M'saho" que a timbila ganhou ainda mais notoriedade no seio das comunidades chope.

\section{A Timbila e o Estado, Alguns Desafios}

Com a restituição do "M'saho", este grande evento cultural da timbila que acontece anualmente em Quissico, distrito de Zavala, tornou-se um campo onde se estabelecem diferentes negociações entre a sociedade civil e o Estado, tanto na atribuição de sentido da timbila, quanto na realização do próprio evento. Trata-se de um evento que no período colonial, na década 40 , era da inteira responsabilidade das estruturas tradicionais, e que depois do conflito armado passou a ser organizado pela sociedade civil, até 2017. Contudo, desde 2018, o governo distrital tem assumido a dianteira na organização do "M'saho" e ao assumir esta tarefa o Estado tem sido interpretado pelas associações como um órgão que ao invés de agir como facilitador está diminuindo o papel exercido pelas comunidades. A disputa pelo protagonismo se tornou ainda mais evidente após o reconhecimento a nível mundial da timbila, o que gera uma série de expectativas em torno do prestígio dentro e fora da comunidade.

Segundo Jeudy (2005), a obrigação do Estado no âmbito da salvaguarda do património cultural é fazer com que os praticantes se organizem em associações para a legalização das mesmas e sua consequente operacionalização. Ainda assim, o autor indica que "as organizações mostram resistências à institucionalização dos seus grupos e associações, mesmo sabendo que necessitam de estar registados com vista a se beneficiarem de apoias financeiros (Jeudy, 2005, p. 230). Como pude observar em diversas ocasiões em que estive recolhendo dados com os músicos de timbila, a suposta resistência colocada pelos praticantes nem sempre está associada à falta de interesse e sim, sobretudo, à falta do domínio da leitura e da escrita, lembrando que a maioria dos praticantes de timbila não tem o português como a sua primeira língua, mas sim a língua chope. Mesmo para as associações que estão numa situação regularizada como, por exemplo, a Amizava, têm tido enormes dificuldades para se beneficiar das subvenções nacionais e internacionais, devido à falta de capacidade técnica em matéria de concepção de projectos. Em virtude disso, podemos notar que os praticantes de timbila lançam duras críticas aos servidores do Estado por interpretarem que ao invés capacitá-los com o objectivo de concorrer às subvenções nacionais e internacionais, a política estatal, de um modo mais geral, se aproveitaria da timbila para reforçar os seus projectos políticos, sem uma efectiva participação dos próprios timbileiros. 
Portanto, um dos principais problemas apontados durante a pesquisa é que os canais de diálogo entre as associações de salvaguarda da timbila e o Estado são pouco flexíveis, pois obedecem uma estrutura vertical contraproducente que dificulta aos detentores levantar as suas preocupações prioritárias acerca do património e indicar as possíveis medidas para a solução das tais inquietações. Notamos que parece existir um receio de se estabelecer um diálogo horizontal com os detentores dos patrimónios imateriais que permitam a intervenção das comunidades na avaliação do grau de implementação das acções de salvaguarda.

A importância da co-participação das comunidades ou das associações no acto de avaliação é visto como fundamental, pelo facto de serem as comunidades que no dia a dia enfrentam os desafios da salvaguarda das suas manifestações artísticas. São as comunidades que sabem qual é o valor simbólico que os patrimónios artísticos representam tanto para o fortalecimento da identidade, como na coesão social entre os membros da comunidade. E são os próprios detentores destes saberes que também conhecem o significado das práticas culturais como a timbila para as futuras gerações. Por isso é importante que se compreenda que a gestão compartilhada do património cultural imaterial não pode ser vista como uma confrontação, mas sim como um processo de governação inclusivo onde as comunidades e o Estado, em conjunto, podem encontrar as melhores soluções para o restauração, preservação e divulgação do património cultural.

Contudo, a relação de trabalho entre as associações de timbila e o Estado nem sempre tem sido vista de bom agrado por parte dos governantes moçambicanos. Conforme descreve Jeudy (2005), embora tais associações precisem do poder político para questões de apoio para as acções de sobrevivência da timbila enquanto património cultural imaterial, ao mesmo tempo, elas também têm denunciado supostos constrangimentos cometidos por diferentes esferas do poder estatal. Segundo Jeudy (2005), por temer ser avaliado pelas associações e comunidades, o Estado tem ignorado o princípio de que as artes e culturas passaram a possuir o direito de se organizarem em associações, o que inclui a liberdade de escolher os conteúdos e temáticas a serem retratados nas suas obras, bem como cumprir com aquilo que são as políticas públicas de preservação do património cultural.

Dentro desta concepção de direitos, identifiquei que os praticantes de timbila não estão plenamente de acordo com a interferência impositiva por parte de agentes do Estado, em aspectos que dizem respeito a questões culturais específicas (Chibanga, 2011). Pois, segundo os timbileiros, há dirigentes políticos que tentam influenciar o modo pelo qual os artistas devem tocar e dançar a música de timbila, sem tomar em conta que tal prática obedece a princípios seculares que devem ser respeitados e salvaguardados. Um exemplo concreto desta influência pode ser notado na indicação de repertórios, na indicação de certos músicos, especialmente em eventos oficiais o que, segundo alguns timbileiros, acaba os desmotivando.

A respeito disso, Victor Bernardo, um dos filhos de Bernardo Romeu, exímio tocador e compositor de timbila, considera não ser aconselhável que agentes do Estado ou 
das estruturas governativas tomem decisões sem o consentimento e acordo prévio dos tocadores e praticantes, porque a intervenção ou a interferência das autoridades nem sempre foi bem recebida pelos executores. Por isso, considera ser muito triste este tipo de atitude por parte de pessoas que deviam saber muito mais sobre a timbila (Chibanga, 2011).

Ainda assim, como pude perceber em conversas e entrevistas realizadas com os praticantes de timbila, face a estas imposições, eles acreditam que a visão, o saber e a execução daqueles que sabem tocar irão prevalecer em relação à acção dos que ditam ordens, sem saberem tocar, sem perceberem o contexto cultural, sem saber onde vivem os tocadores, donde é que eles vêm. Portanto, para a preservação deste património e seguindo as recomendações da Unesco é fundamental que o Estado esteja disposto a ouvir como os próprios praticantes gostariam que decorressem os "Misaho"1 a selecção do repertório, a maneira de estar no palco, a escolha do traje de forma livre e sem qualquer imposição externa.

Este parece um processo delicado já que se verifica que os discursos oficiais em prol da timbila, além de enaltecerem e valorizarem os métodos e procedimentos recorridos pelos chopes para a sua valorização e preservação, buscam conferir novos sentidos com para a prática que não necessariamente represente a história da timbila. Isso é feito, por exemplo, através de certo esquecimento oficial sobre diversos mestres e compositores que marcaram os diferentes contextos da música e dança e que mereciam um lugar na memória oficial, através de publicação de materiais. Pouca menção tem sido feita sobre a relevância da memória colectiva e da oralidade na (re)construção da identidade do povo chope, bem como os papéis sociais exercidos pelas instituições sociais na preservação desde legado. E estes são outros grandes desafios institucionais que precisam ser encarados e solucionados.

Contudo, é possível perceber que, no contexto das manifestações culturais, a narrativa política tem situado a timbila como um símbolo de unidade nacional. Porém é preciso ter cuidado para que a salvaguarda de um património não motive qualquer constrangimento étnico que possa promover qualquer desestabilização no país. Neste sentido, acreditamos que a timbila, enquanto um património do país (e não apenas dos chopes) deve ser reconhecida em toda sua complexidade social e histórica que permita sua preservação e salvaguardo sem que precise atender a supostos interesses políticos ideológicos. Por isso, a narrativa do Estado não deve se traduzir como um acto desarticulador e muito menos ignorar o universo simbólico do qual a timbila faz parte. Pelo contrário, o Estado deve actuar como facilitador e consolidador do processo de salvaguarda, pautado por um modelo de comunicação eficaz, assente no respeito pela música e dança de timbila dentro do seu contexto de inserção.

\section{A Timbila e a Educação Universitária}

Desde que a Universidade Eduardo Mondlane (UEM), localizada na capital do país, Maputo, introduziu o curso de Música, a timbila foi considera como uma das prioridades a

1 Na língua chope, a palavra "Misaho" significa o plural de "M’saho". 
ser introduzida no programa de ensino universitário. No âmbito da salvaguarda, a inserção da timbila abriu novos caminhos e possibilidades para existência de uma educação patrimonial, capaz de levar a sociedade a ter uma visão sobre as suas raízes culturais de forma mais definida e mais estável, ao ponto de the conferir o sentido de apropriação e de valorização de sua herança cultural, bem como ensinar a respeitar a diversidade cultural. Foi a partir desta linha orientadora que, a disciplina de timbila passou a fazer parte do programa do curso de licenciatura em Música, na UEM, em 2006.

A introdução desta disciplina não somente veio projectar a divulgação e a valorização da timbila como veio contribuir para a inclusão epistémica, visto que esta prática tal como muitas outras de tradição oral é, na maioria das vezes, colocada na periferia dos centros de saber. Ao se colocar as práticas culturais de matriz africana fora das universidades, como o caso da timbila, não se tomou em conta que os saberes das expressões musicais de tradição oral, bem como seus modos informais de transmissão e aprendizagem constituem, de acordo com Carvalho et al. (2017), "um riquíssimo corpus teórico-prático" (p. 202) que, se incorporado ao currículo universitário, pode revelar outras formas e pedagogias de aprendizagem, abrindo assim novas possibilidades e alternativas metodológicas relativamente aos modelos europeus instituídos nas universidades e nas escolas de música.

De certo modo, isto veio demonstrar que as práticas musicais da tradição oral são tão importantes quanto as músicas eruditas do mundo ocidental. A valorização da timbila enquanto património cultural imaterial da humanidade, constitui um grande contributo para Moçambique e para humanidade, uma vez que são saberes que, segundo Carvalho et al. (2017), foram no passado recente relegados dos centros da academia justamente pelo motivo de serem provenientes dos povos que sofreram a violência das estruturas de poder colonial, que por mais de 5 séculos os colocaram fora do recinto académico e dos currículos formais, apenas por não possuir literatura escrita e por possuir um padrão musical diferente daquele que a comunidade científica legitimou como ciência.

Actualmente, num contexto onde a democratização do saber tem propiciado encontros de saberes, somos estimulados a pensar o futuro da timbila no processo de ensino e aprendizagem dentro dos recintos académicos. Pois, o facto de a timbila fazer parte do programa do currículo de ensino de música não deve ser visto como um processo acabado, já que existem outros desafios por enfrentar. Temos verificado que os alunos formados em timbila ainda estão abaixo do limiar da execução instrumental, quando comparado com os tocadores formados no contexto da educação informal. Estes estudantes não necessariamente demonstram o conhecimento e a técnica exigida para uma peça musical, do qual constitui o “M’saho", por exemplo.

Percebe-se que o ensino de timbila demonstra certa desarticulação com o contexto original da timbila, pelo facto de não se submeter aos padrões da própria música, tal como: a estrutura, os movimentos a que ela se subordina, e sobretudo, a linguagem da qual é portadora. Acreditamos que caso pretenda-se levar avante as acções de salvaguarda da timbila nas instituições de ensino superior, a metodologia de ensino 
não deve ocorrer de forma aleatória e muito menos fora do sistema musical. Neste caso, recomenda-se ensinar a timbila de tal modo que o estudante, ao fim de sua formação, possa ter a capacidade de conhecer e tocar todos os movimentos musicais, obedecendo a estrutura e a linguagem do sistema musical do qual a timbila faz parte. Para tanto, a transferência desse saber patrimonial para a universidade deve ser efectuado com a participação dos "mestres" ${ }^{2}$ detentores em actividades de leccionamento no espaço universitário, pois acreditamos que a vivência com os mestres oferece aos estudantes a possibilidade de conhecer e aprofundar os saberes relacionados a timbila, tal como ela é concebida no seu contexto de inserção. A inserção destes mestres no processo de ensino aprendizagem - não somente na vertente timbila - confere aos estudantes ferramentas para que possam ser os professores do amanhã, de maneira a darem efectiva continuidade à transmissão desse saber à outras gerações.

\section{Timbila e a Inventariação do Património Cultural Imaterial}

Em torno do registo, arquivo e documentação de conteúdos relacionados com a timbila chope no âmbito da sua salvaguarda é importante mencionar o papel desempenhado pelo ARPAC que "iniciou as suas actividades em 1983, na forma de um projecto que entre outros fins, visava assegurar os destinos dos documentos recolhidos durante a Campanha Nacional de Preservação e Valorização da Cultura que teve lugar entre 1978 à 1982" (ARPAC - Instituto de Investigação Sócio-Cultural, s.d.). Por meio do Decreto n. ${ }^{\circ}$ 26/93 de 16 de novembro de 1993, o ARPAC deixou de ser um projecto se transformando em instituição com o nome de "Arquivo Histórico Moçambicano". Posteriormente, esta sigla passou a corresponder ao Instituto de Investigação Sócio-Cultural através do Decreto n. ${ }^{\circ}$ 25/2002 (2002). Esta instituição de acordo com o Capítulo 1, Artigo 1 do seu estatuto orgânico possui as seguintes atribuições (Decreto n. ${ }^{\circ}$ 26/93, 1993):

- pesquisar, registar, arquivar, documentar, conservar e divulgar para o grande público as informações referentes a sua área de especialidade;

- arquivar os processos de bens classificados do património cultural laborados de acordo com o regulamento da lei de protecção do património cultural;

- promover a educação cultural dos moçambicanos de modo a reforçar a sua identidade cultural e envolvê-los na apreciação, valorização e protecção da cultura e património cultural;

- organizar bibliotecas e centros de documentação especializada e incentivar todas as acções e iniciativas que envolvem pesquisa, bibliografia, e documental sobre o património cultural moçambicano.

2 "Quando se fala em 'mestres' dos saberes tradicionais, esta se referindo a pessoas que detém o conhecimento em suas respectivas áreas de actuação, porem sem ter constituído qualquer tipo de formação académica" (Carvalho et al., 2017, p. 6). 
Já o Artigo 12 da Convenção Para a Salvaguarda do Património Cultural Imaterial (2003) defende que

para assegurar a identificação, com fins de salvaguarda, cada Estado parte estabelecerá um ou mais inventários do património cultural imaterial presente em seu território, em conformidade com seu próprio sistema de salvaguarda do património. Os referidos inventários serão actualizados regularmente. (p. 8)

É com base neste pressuposto que, em 2016, o ARPAC realizou o inventário comunitário do distrito de Zavala. 0 objectivo desse inventário visou produzir uma série de informações em torno da timbila, com finalidade de apetrechar a biblioteca, com documentários audiovisuais, $C D$ s, livros e revistas relacionadas com a timbila chope. Neste sentido, o trabalho levado a cabo pelo ARPAC buscou inventariar todos os actores directamente ligados a timbila chope, incluindo, fabricantes de instrumentos, tocadores e dançarinos de diferentes zonas onde se pratica a música e a dança chope.

A inventariação partiu da pesquisa e da recolha de componentes que fossem classificáveis como timbila chope (instrumento, música, letra e indumentária). Apesar dos avanços, um dos desafios que tem afectado as instituições de pesquisa refere-se à falta de sistematização desses materiais recolhidos que dificultam a disponibilização pública de parte significativa dos materiais colectados. Este elemento dificulta o cumprimento das obrigações recomendadas pela Unesco, enquanto entidade reguladora e fiscalizadora do processo de salvaguarda dos bens patrimoniais.

Por isso, a questão da sistematização da documentação referente aos instrumentos, às músicas e às danças chope, assim como a inventariação de elementos ou objectos e conteúdos relacionados à timbila chope devem ser consideradas como factores determinantes no processo de registo e de salvaguarda deste legado. E, neste caso, o maior desafio das instituições, e para o ARPAC, é que esse material inventariado seja de acesso público. E, talvez, o modo mais eficaz seja a digitalização e disponibilização do material em plataforma web.

\section{A Timbila e a Salvaguarda do Mwenje}

Mwenje é uma árvore bastante rígida usada para o fabrico de timbila. Normalmente é plantada na época em que a árvore começa a dar novas folhas. Esta árvore tem um crescimento bastante moroso, que leva sensivelmente 60 anos para estar em condições de ser usada para a fabricação de teclas de timbila, as chamadas "makhokhomas". Esta árvore dá os seus frutos no mês de novembro e depois de dar fruto leva 4 semanas para as sementes se abrirem.

Durante a pesquisa para a confecção do inventário realizado em Zavala, observamos que para uma eficaz salvaguarda da timbila, a questão do acesso ao mwenje constitui um desafio preocupante, especialmente porque esta árvore corre o risco de extinção. A respeito disso, Luís Semende Massotchuane, que toca na orquestra de Nhakutowo, informou que foi o primeiro construtor de timbila a dedicar-se ao plantio de mwenje, 
a partir de 1979, sendo dos mais conhecidos em Mavila, localizado no distrito de Zavala, província de Inhambane. Custódio Pitula também é um dos que abraçou a causa da preservação da timbila chope, iniciando em dezembro de 2008 o plantio de cerca de 450 viveiros de mwenje. Face a este desafio, Venâncio Mbande alertou-nos que o mwenje começou a escassear no período da guerra devido ao abate descontrolado, especialmente para o fabrico de carvão o que constitui um dos motivos para a sua escassez. Para ele, o abate irracional reside na falta de conhecimento por parte dos carvoeiros sobre a importância do mwenje, enquanto matéria-prima para a fabricação da timbila. Portanto, o desconhecimento sobre a importância da mwenje afecta a preservação da e salvaguardo da própria timbila (Chibanga, 2011).

Neste sentido, salvaguardar a timbila chope pressupõe antes de mais nada salvaguardar a matéria-prima que condiciona o fabrico do instrumento. Para tal, a preservação só poderá ser efectiva através de uma acção conjunta envolvendo pesquisadores de instituições culturais em conjunto com os investigadores do campo da ecologia, cujos saberes podem ajudar na preservação e a multiplicação do mwenje de forma massiva. Neste sentido, acreditamos que a educação contínua sobre as técnicas de plantio e os cuidados do mwenje precisa ser difundida em conjunto com as instituições agrárias do país e argumentamos que o plantio de mwenje e o consequente aumento de mais instrumentos poderá contribuir para o aumento de um número de praticantes de timbila chope.

Importante situar que o governo do distrito de Zavala tem-se preocupado com a gestão do mwenje. Contudo, durante pesquisa realizada para a confecção do inventário, identificamos que o modo de distribuição nem sempre é consensual entre os fabricantes destes instrumentos, pois os mesmos reclamam que a distribuição tem sido entregue a grupos que, embora executem a timbila, desconhecem a efectiva arte do seu fabrico. Neste âmbito, consideramos que deve-se implementar uma distribuição equitativa de modo a abranger efectivamente os vários fabricantes de timbila chope. Alguns entrevistados informaram que "antigamente" as autoridades tradicionais, a exemplo dos régulos, desempenhavam um papel preponderante na música chope, já que se responsabilizavam pela gestão e pela protecção do mwenje. Neste contexto, destacamos a importância da participação e envolvimento dos líderes comunitários no processo de distribuição dos materiais para a construção dos instrumentos.

Portanto, os dados colectados através do inventário realizado em Zavala indicam que a baixa participação destas autoridades tradicionais no processo de salvaguarda do mwenje é outro desafio a ser enfrentado, levando em consideração que estes sujeitos sociais ocupam um papel de liderança nas comunidades e, por conseguinte, gozam de um enorme poder na disseminação das mensagens. Sendo assim, tudo aponta para a ideia de que somente acções concertadas, envolvendo uma diversidade de agentes como a educação, as organizações não governamentais, os meios de comunicação, a sociedade civil, instituições ligadas à preservação da flora e da fauna, é que poderão, efectivamente, alicerçar uma base que contribua para a devida salvaguarda da timbila chope. Obviamente, para uma efectiva gestão dos planos de salvaguarda, conforme atesta a nossa pesquisa, impõe-se uma harmonização efectiva das actividades dos 
vários intervenientes culturais a fim de evitar a duplicação e sobreposição de responsabilidades; promover e coordenar com os diferentes intervenientes que abraçam a causa da preservação, protecção e promoção da timbila chope a realização de acções concertadas e complementares.

\section{Conclusão}

Apesar de Moçambique ter dado passos significativos no que diz respeito às medidas de salvaguarda da timbila, ainda enfrenta inúmeros desafios como aqueles identificados neste artigo. 0 primeiro deles tem sido a relação entre as instituições do Estado e os praticantes de timbila, caracterizado por certa interferência de parte dos agentes estatais que deveriam concentrar seus esforços em realizar políticas públicas para a capacitação das associações ou das comunidades, em matéria de gestão do património cultural imaterial.

No que se refere à educação da timbila na universidade, esta parece uma iniciativa importante mas que precisa da presença dos mestres da timbila para um conhecimento mais aprofundado e contextual a ser oferecido aos alunos. Sob o ponto de vista da inventariação da timbila realizada em Zavala, em 2016, esta aponta para a necessidade das pesquisas e recolhas de componentes relacionadas com a timbila chope abordarem tudo o que seja classificável como timbila chope (instrumento, música, letra, indumentária), incluindo os materiais necessários para a construção dos instrumentos. Neste caso, ressalta-se a escassez do mwenje que, segundo os fabricantes de timbila, é consequência do desconhecimento por parte da comunidade que tem feito abates de árvores para o fabrico de lenha para cozinha. Ainda no que se refe ao mwenje, argumentamos que constitui um bem a ser difundido e preservado através de uma educação formal e informal, onde no sector informal os líderes tradicionais poderão desempenhar um papel de relevo. Afinal, o “M'saho", como forma de transmissão lúdica, constitui uma metodologia didáctica eficiente visando uma assimilação mais rápida e eficaz sobre a timbila e outros saberes a ela associados, transmitidos ao longo dos períodos que antecedem à sua realização.

Finalmente recomenda-se que o Estado se abra, cada vez mais, para uma participação efectiva dos detentores da timbila no complexo processo de salvaguarda deste bem cultural imaterial, como prevêm as convenções da Unesco (Convenção Para a Protecção e Promoção da Diversidade das Expressões Culturais, 2005; Convenção Para a Salvaguarda do Património Cultural Imaterial, 2003) ratificadas por Moçambique.

\section{Referências}

ARPAC - Instituto de Investigação Sócio-Cultural. (s.d.). Quem somos. http://www.arpac.gov.mz/index. php/sobre-arpac/quem-somos

Carvalho, J. J., Cohen, L. B., Ferreira, A., \& Chada, S. (2017). 0 encontro de saberes como uma contribuição à etnomusicologia e à educação musical. In A. Lühning \& R. P. Tugny (Eds.), Etnomusicologia no Brasil (pp. 191-227). Editora da Universidade Federal da Bahia (EUFB). 
Chibanga, V. (2011). Papel da comunicação do processo de salvaguarda da Timbila chope como património da humanidade [Tese de licenciatura não publicada, Universidade Politécnica].

Convenção para a protecção e promoção da diversidade das expressões culturais, 20 de outubro, 2005, http://www.ibermuseus.org/wp-content/uploads/2014/07/convencao-sobre-a-diversidade-das-expressoes-culturais-unesco-2005.pdf

Convenção para a salvaguarda do património cultural imaterial, 17 de outubro, 2003, http://portal.iphan. gov.br/uploads/ckfinder/arquivos/ConvencaoSalvaguarda.pdf

Decreto no 25/2002, de 22 de Outubro. (2002).

Decreto n-26/93 de 16 de Novembro. (1993).

Jeudy, H. (2005). Espelho das cidades. Casa da Palavra.

Jopela, V. (2006). Para uma caracterização da poesia oral nas timbila dos vacopi e alguns aspectos do contributo português 1940-2005 [Tese de doutoramento, Universidade Clássica de Lisboa].

Junod, H., \& Alexandre, A. (1996). Usos e costumes dos Bantus. Arquivo Histórico de Moçambique.

Lutero, M. (1981). Apontamentos sobre a música popular e tradicional em Moçambique. MEC.

Munguambe, A. D. (2000). Música chope. Promédia.

Tracey, H. (1949). A música chope: Gentes afortunadas. Imprensa Nacional de Moçambique.

Wane, M. (2010). A timbila chopi: Construção de identidade étnica e política da diversidade cultural em Moçambique (1934-2005) [Dissertação de mestrado, Universidade Federal da Bahia]. Repositório Institucional. https://repositorio.ufba.br/ri/handle/ri/15082 